\title{
METABOLISM OF ACETYLCHOLINE RECEPTORS ON EMBRYONIC AMPHIBIAN MUSCLE ${ }^{1}$
}

\author{
PAUL BREHM, ${ }^{2}$ ELAINE YEH, ${ }^{3}$ JIM PATRICK, AND YOSHIAKI KIDOKORO \\ The Salk Institute, San Diego, California 92138
}

Received March 30, 1982; Revised July 27, 1982; Accepted August 5, 1982

\begin{abstract}
The functional properties of acetylcholine receptors are altered during the development of Xenopus myotomal muscle. A similar change also occurs in dissociated cell cultures of embryonic myotomal muscle. Metabolism of acetylcholine receptors was examined in order to ascertain whether the turnover rate changed at a time when the functional changes were detected. Incorporation of newly synthesized receptors occurred at a constant rate over a 24-hr period. The degradation of receptors followed first order kinetics with a half-life of $52 \mathrm{hr}$. Incorporation and degradation occurred at approximately equal rates such that 1 to $1.5 \%$ of the total receptor number was replaced every hour at equilibrium. Addition of neural tube cells to muscle cell culture, which altered the functional properties of channels, had no effect on either the incorporation or the degradation rate. We conclude that the changes in the functional properties of receptors occur independent of changes in the turnover rate of receptors.
\end{abstract}

During development of skeletal muscle there occur alterations in the functional and biochemical properties of acetylcholine (ACh) receptors. The mean channel open time (Sakmann and Brenner, 1978; Schuetze and Fischbach, 1978; Fischbach and Schuetze, 1980; Michler and Sakmann, 1980), the expression of antigenic sites (Reiness and Hall, 1981), and the metabolic stability of receptors (Michler and Sakmann, 1980; Reiness and Weinberg, 1982) all change following innervation of embryonic rat muscle. Separate studies have indicated that the timing of these various changes is sequential rather than synchronous (Michler and Sakmann, 1980; Reiness and Weinberg, 1982). This suggests that the different receptor properties are determined independently in

\footnotetext{
' We are grateful to Drs. R. Kullberg and J. H. Steinbach for helpful discussions during the course of the project. Dr. S. Heinemann provided expert technical assistance running the P-2 column. Comments concerning the manuscript by Drs. P. DeCino, K. Dunlap, and P. MoodyCorbett are greatly appreciated. The project was funded by National Institutes of Health Grants NS11918 to Y. K. and NS13546 to J. P. and Muscular Dystrophy Association grants to Y. K. and J. P. P. B. was supported by a postdoctoral fellowship from the Muscular Dystrophy Association and by the Galster Foundation.

${ }^{2}$ To whom correspondence should be addressed at his present address: Department of Physiology, Tufts University School of Medicine, 136 Harrison Avenue, Boston, MA 02111.

${ }^{3}$ Present address: Department of Biological Science, University of California, Santa Barbara, Santa Barbara, CA 93106.
}

mammalian muscle. This idea is supported by the observation that, in chick muscle, changes in the metabolic turnover rate of ACh receptors occur (Burden, 1977) without any change in the functional properties (Schuetze, 1980).

The mean channel open time of $\mathrm{ACh}$ receptors on embryonic Xenopus muscle decreases during embryonic development (Kullberg et al., 1981). Further studies indicate that similar functional changes occur in dissociated embryonic muscle (Brehm et al., 1982). In this study we utilize the advantages of cell culture to examine whether the change in functional properties of $\mathrm{ACh}$ receptors on Xenopus muscle is associated with a change in their metabolic stability. To this end we compared receptor turnover of muscle cultured alone to muscle cocultured with neural tube cells. Coculture with neural tubes prolongs the channel open time of receptors in Xenopus muscle (Brehm et al., 1982).

We report that the receptors on Xenopus myotomal muscle are degraded with a half-life of $52 \mathrm{hr}$ in culture. No detectable change in this rate was observed when muscle was cocultured with dissociated neural tube cells. Additionally, no change occurred in the incorporation rate of newly synthesized receptors when the muscle was cocultured with neural tube cells. We conclude that ACh receptors on embryonic Xenopus muscle, like those on mammalian muscle, undergo changes in functional properties which can occur independent of a measurable change in metabolic properties. 


\section{Materials and Methods}

Cell culture. Techniques for preparing cell cultures of myotomal muscle from Xenopus laevis embryos are detailed elsewhere (Kidokoro et al., 1980). Typically, muscle cells from 120 to 180 embryos (stages 19 to 24) were used for a single experiment. The myotomal muscle was separated from the neural tube by treatment with collagenase and subsequent dissociation in a $\mathrm{Ca} / \mathrm{Mg}$-free $+2 \mathrm{~mm}$ EDTA ((ethylene-dinitrilo)tetraacetic acid) solution. Dissociated myotomal muscle cells were added to a centrifuge tube containing approximately $10 \mathrm{ml}$ of growth medium (60\% Dulbecco's Modified Eagle's Medium, 8 mM HEPES buffer at $\mathrm{pH} 7.4,0.5 \%$ horse serum) and the tube was rotated continuously to keep the cells in even suspension while $200-\mu$ l aliquots were drawn off and added to each culture dish. Using this technique, up to 60 cultures with uniform cell density could routinely be prepared. The cells were grown in disposable chambers which were constructed from 35-mm Petri dishes. A 15$\mathrm{mm}$ hole was drilled in the bottom half of the dish over which a collagen-coated coverslip was waxed in place. At the time of plating, only enough growth medium was added to fill the depression in the middle of the chamber, thereby restricting the cells to the region bounded by the collagen-coated coverslip. After $24 \mathrm{hr}$ the cells were adherent to the coverslip and the dish was flooded with an additional $2 \mathrm{ml}$ of growth medium. Cultures prepared in this manner were grown at 20 to $22^{\circ} \mathrm{C}$ for a maximum period of 6 days. The earliest experimental measurements were made on day 1 which corresponded to $24 \mathrm{hr}$ following plating.

Some experiments were directed at testing the influence of neural tube cells on the turnover of ACh receptors. For this purpose neural tube cells from 120 to 180 embryos were added to 30 muscle cultures, either at the time of muscle plating or 3 days after plating the muscle. When neural tube cells were added 3 days after the muscle, $2 \mathrm{ml}$ of growth medium were removed to restrict neuronal cells to the coverslip region. After $24 \mathrm{hr}$ an additional $2 \mathrm{ml}$ of growth medium were added.

Labeling cultures with ${ }^{125} I-\alpha$-bungarotoxin. $\alpha$-Bungarotoxin ( $\alpha-\mathrm{BT})$ was purified from the venom of Bungarus multicinctus. The $\alpha$-BT was iodinated using the iodine monochloride method (Vogel et al., 1972). Mono and diiodo toxins were separated by chromatography on CMSephadex and only diiodo-labeled $\alpha$-BT was used in these experiments. The specific activity of the ${ }^{125} \mathrm{I}-\alpha$-BT ranged from 8.9 to $9.9 \times 10^{8} \mathrm{cpm} / \mathrm{nmol}$.

Time-dependent changes in ACh receptor number were quantitated by measuring the specific binding of ${ }^{125} \mathrm{I}-\alpha-\mathrm{BT}$. Only cultures prepared from the same plating were used during a single experiment. Also, in order to minimize the potential problem of systematic differences in cell number between dishes, all dishes were randomly sorted prior to labeling. At each experimental time point cultures were washed with $2 \mathrm{ml}$ of growth medium to remove nonadherent cells. The cultures then were incubated for $60 \mathrm{~min}$ in $40 \mathrm{nM}{ }^{125} \mathrm{I}-\alpha$-BT at room temperature. Dose response curves indicated that this concentration, when applied for $60 \mathrm{~min}$, saturated receptors on Xenopus myotomal muscle. After incubation in toxin, the cultures were washed six times with growth medium. Generally, the washing of cultures at each time point was completed within a 10-min period. Then the coverslip was separated from the Petri dish and was placed in a vial for gamma counting.

The nonspecific binding of ${ }^{125} \mathrm{I}-\alpha$-BT routinely was measured by pretreating sister muscle cultures with $1 \mu \mathrm{M}$ unlabeled $\alpha$-BT for $60 \mathrm{~min}$ prior to addition of ${ }^{125} \mathrm{I}-\alpha$-BT. The nonspecific binding measured less than $10 \%$ of the total counts. Nonspecific binding also was estimated independently by competition with tubocurarine. Cultures were treated for $60 \mathrm{~min}$ with $10 \mu \mathrm{M} d$-tubocurarine after which time $40 \mathrm{nM}{ }^{125} \mathrm{I}-\alpha$-BT was added. The nonspecific binding measured in this way was also less than $10 \%$ of the total counts.

Incorporation of newly synthesized receptors was measured by pretreating cultures with $1 \mu \mathrm{M}$ unlabeled toxin for $1 \mathrm{hr}$ to block existing receptors. Unbound toxin was removed by washing and the cultures were returned to the growth medium. At successive intervals following the block, triplicate cultures were treated with $40 \mathrm{nM}{ }^{125} \mathrm{I}-$ $\alpha-\mathrm{BT}$ in order to quantitate the appearance of new receptors. Sister cultures which were not treated with unlabeled toxin served to measure the time-dependent changes in the total number of receptors.

The rate of receptor degradation was determined by measuring the time-dependent release of radioactive diiodotyrosine into the growth medium. Cell cultures were labeled at time zero with ${ }^{125} \mathrm{I}-\alpha-\mathrm{BT}$ and unbound toxin was washed out. At successive intervals of approximately $6 \mathrm{hr}$ each, triplicate cultures were counted. The growth medium was removed and was counted separately from the coverslip. To correct for release of nondegraded toxin, the medium from at least one culture at each time point was run on a P-2 column. At each time point the ratio of high molecular weight to low molecular weight counts was used to compute the actual amount of counts contributed by the degraded toxin. The high molecular weight species represents the nondegraded toxin-receptor complex and the low molecular weight species represents free diiodotyrosine resulting from degradation of the toxin (Berg and Hall, 1975; Devreotes and Fambrough, 1975). Approximately 50\% of the counts eluted as high molecular weight species at the first time point but no additional release of high molecular weight counts was observed over the following $70 \mathrm{hr}$. The rate of receptor degradation then was computed for each culture by plotting the fractional amount of counts contributed by the low molecular weight species at each time point. The average lifetime of the ACh receptor was estimated from the time necessary for half of the toxin molecules in each culture to be degraded.

\section{Results}

Time-dependent changes in receptor number. Timedependent changes in receptor number were quantitated by measuring the specific binding of ${ }^{125} \mathrm{I}-\alpha$-BT over a 6 day cell culture period. In order to translate the measured change in binding into a change in the relative number of receptors it was necessary to demonstrate the specificity of toxin binding. That ${ }^{125} \mathrm{I}-\alpha$-BT bound specifically to the nicotinic ACh receptor was shown by blocking over $90 \%$ of the binding by coincubation of labeled toxin with 
the competitive antagonist $d$-tubocurare. Therefore, it was reasonable to assume that time-dependent changes in binding reflected a change in the number of exposed nicotinic ACh receptors. It was also reasonable to assume that the specific binding was restricted to muscle cells. The nonmuscle cell types were observed infrequently in these cultures and such cells showed no specific binding of ${ }^{125} \mathrm{I}-\alpha-\mathrm{BT}$ when measured by the autoradiographic technique (Kidokoro and Gruener, 1982).

The change in receptor number over the 6-day period was first examined in muscle cultures to which no neural tube cells were added. The results of three separate experiments (Fig. 1) indicated at least a 2 -fold increase in binding during the first 4 days in culture and little change after day 5 . Since these myotomal muscle cells do not divide in culture (Anderson and Cohen, 1977), this result indicates that individual muscle cells increase the number of surface receptors between days 1 and 4 in culture.

The increase in receptor number occurred during a period of cell growth and differentiation in vitro (Fig. 1). The 6-day period is also the time over which changes of cell number as a result of cell death are minimal. Measurements of the rate of change in cell size indicated a good correspondence between the change in cell surface area and receptor number (Fig. 1). The change in surface area may have resulted from a smoothing of convoluted membrane which existed at the time of dissociation, in which case the apparent growth would reflect the stretching of existing membrane. We excluded this possibility by removing adherent cells on days 2 through 6 with collagenase and measuring the diameter of the resultant "myoball." The predicted surface area, based on the spherical "myoball" diameter on the 5 successive days corroborated the directly measured change in surface area. The fact that the rate of growth and the rate of receptor accumulation were similar suggests that the increase in receptor number did not result in a dramatic change in mean receptor density as the cells grew.

The effect of neural tube cells on receptor number was studied by comparing muscle cultures with sister cultures to which neural tube cells had been cocultured for 3 days. The 3-day coculture period was the time over which the addition of neural tube affected receptor function on both nerve-contacted and noncontacted muscle cell (Brehm et al., 1982). The results of four separate experiments indicated that the neural tube had no measurable effect on the total number of receptors (Table I). This finding corroborates the autoradiographic study of $\mathrm{Ki}$ dokoro and Gruener (1982) which reported no effect of neural tube on nonsynaptic receptor density on cultured Xenopus muscle.

Receptor incorporation. The observation that the total number of ACh receptors increased during the first 4 days in culture (Fig. 1) implies that receptor incorporation occurred faster than receptor degradation over this time period. This inference was tested by measuring the receptor incorporation rate to compare directly to the rate of receptor degradation (next section). In each of seven separate experiments, measurable binding sites appeared within $6 \mathrm{hr}$ following the block of all existing receptors with unlabeled toxin. The relationship between the appearance of binding sites and the time following the block was nonlinear in each experiment (Fig. 2). For reasons discussed below, it is likely that over measurement periods of less than $24 \mathrm{hr}$ incorporation occurred at a constant rate; the nonlinear accumulation of receptors resulted from the simultaneous first order degradation process. We measured the initial incorporation rate as the slope between 0 and $6 \mathrm{hr}$ following the block (Fig. 2). This slope then was recomputed in terms of the fraction of equilibrium receptors replaced per hour, where the equilibrium receptor number was measured on unblocked sister cultures on day 6 . This normalization proved to be necessary due to the variation in the number of cells between experiments and the change in the total number of receptors over time in culture. The normalized incorporation rate for seven experiments indicates that an average of $1.2 \pm 0.2 \%$ of the equilibrium number of receptors were replaced every hour at equilibrium (Table II).

The incorporation of newly synthesized ACh receptors was nonlinear in every experiment, regardless of the age of the cultures and the incorporation rate. This is illustrated in Figure 2 where incorporation was examined directly in sister muscle cultures on day 1 and on day 4 . In this experiment the absolute incorporation rate per culture decreased over the 4-day period from $0.3 \mathrm{fmol}$ of binding sites per hour measured on day 1 to $0.26 \mathrm{fmol}$ on day 4. Directly measured receptor incorporation is predicted to be nonlinear under conditions in which all receptors are subject to a first order degradation process (Card-Linden and Fambrough, 1979). Using the quantitative treatment provided by Card-Linden and Fambrough (1979) (see Fig. 2), the appearance of receptors can be well described by the degradation rate constant of $72 \mathrm{hr}^{-1}$ (see below) and the incorporation rate measured as the slope between 0 and $6 \mathrm{hr}$ (Fig. 2). The predicted relationship for both day 1 and day 4 (shown by a solid line in Fig. 2) describes well the actual data points after $6 \mathrm{hr}$. This supports a model in which receptor incorporation occurs at a rate which can be considered approximately constant over the measurement period of $40 \mathrm{hr}$.

Receptor degradation. Degradation of ACh receptors on muscle cells cultured alone and muscle cells cocultured with neural tube cells both followed first order kinetics. The fraction of specific counts remaining bound over time followed a logarithmic decrease in each of six experiments (Fig. 3). From these data a mean half-life of the ACh receptor in five experiments was estimated to be $52 \mathrm{hr}$ at $20^{\circ} \mathrm{C}$, corresponding to a rate constant of 72 $\mathrm{hr}^{-1}$. This rate of degradation indicates that $1.4 \%$ of the cell surface receptors were degraded every hour. The cumulative data from the five experiments indicated that the estimated degradation rate is not a function of the age of the culture cells (Table III). Neither was the degradation rate affected by coculturing the muscle cells with neural tube (Table III). This finding is consistent with the data in Table I indicating that addition of neural tube cells to muscle cell culture did not affect the number of receptors on muscle cell surface.

The estimates of degradation rate are predicated on the released radioactivity being in the form of diiodotyrosine. It was possible, however, that the release of ra- 

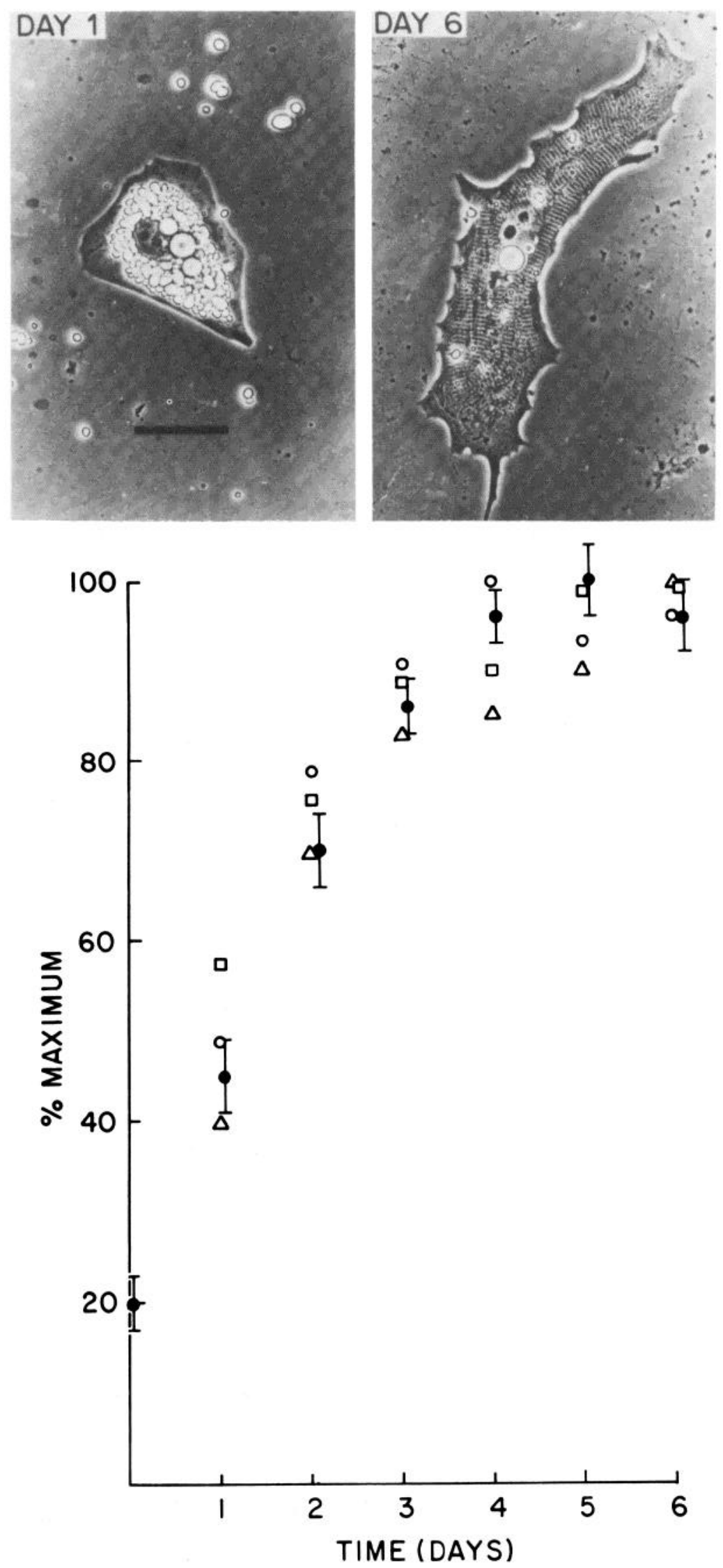

Figure 1. Top, Muscle cells photographed $24 \mathrm{hr}$ and 6 days after dissociation. Bar, $40 \mu \mathrm{m}$. Bottom, The receptor number in sister muscle cell cultures was quantitated by ${ }^{125} \mathrm{I}-\alpha$-BT binding and was plotted as a percentage of the maximum binding observed. Each open symbol indicates the mean of four sister cultures, and the three different open symbols represent three different experiments. The change in mean cell size (SEM indicated by bars) is indicated by solid circles and is plotted as a percentage of the maximum cell surface area. The surface area was measured by integrating the area of a photograph of each cell. This resultant area then was doubled to estimate the total surface area of the cell. Each point is computed on surface area measurements of 75 cells in three cultures between days 1 and 6 . 
dioactivity resulted from dissociation of the toxin-receptor complex. To ensure that the latter was not occurring, we separated low from high molecular weight label. The low molecular weight species represents free diiodotyosine resulting from degradation of receptor-toxin complexes, while the high molecular weight species corre-

TABLE I

Toxin binding sites on 3-day nerve-muscle and sister muscle cultures

\begin{tabular}{ccc}
\hline \multirow{2}{*}{ Experiment No. } & \multicolumn{2}{c}{ Toxin Binding Sites (fmol) } \\
\cline { 2 - 3 } & \multicolumn{3}{c}{ Muscle } & Nerve-Muscle \\
\hline & \multicolumn{2}{c}{ mean $\pm S D$} \\
1 & $27 \pm 1.3(4)^{a}$ & $26 \pm 4.2(4)$ \\
3 & $11 \pm 2(20)$ & $12 \pm 1.7(22)$ \\
4 & $21 \pm 3.4(6)$ & $21 \pm 3.2(6)$ \\
& $35 \pm 4.4(5)$ & $43 \pm 2.5(3)$ \\
\hline
\end{tabular}

${ }^{a} N$ value is indicated by numbers in parentheses.

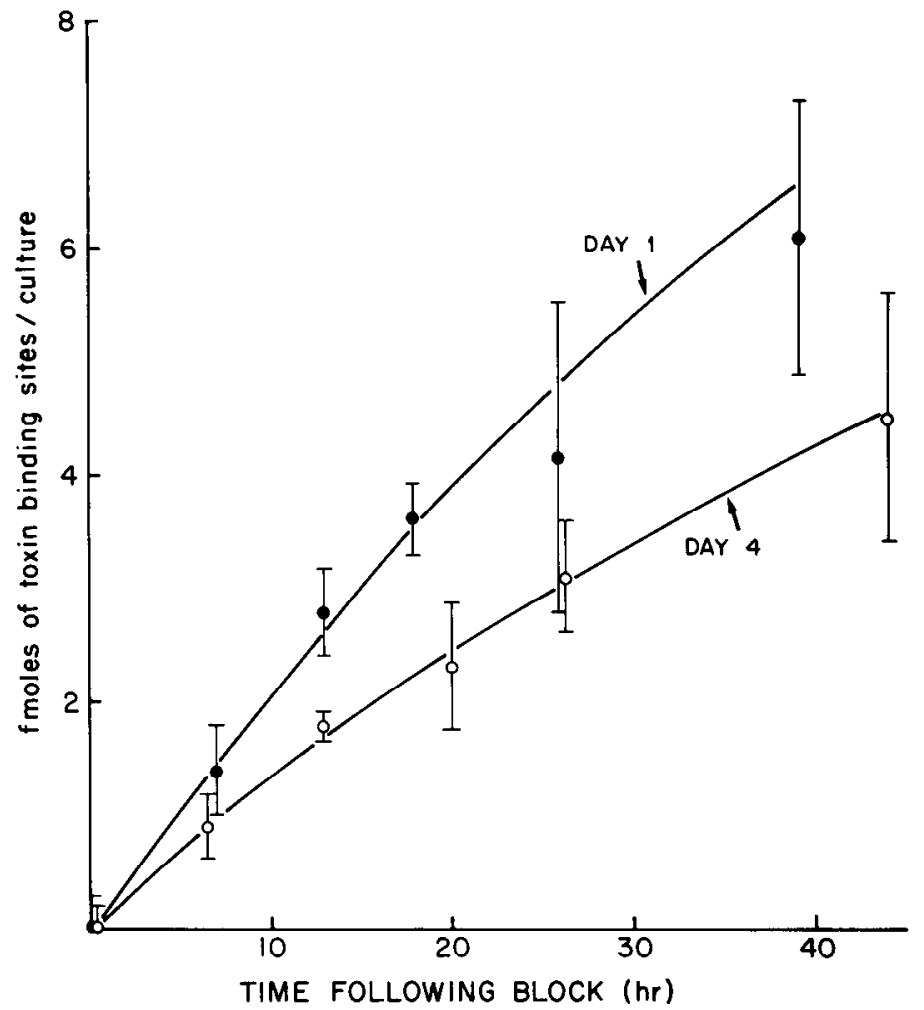

Figure 2. Incorporation of newly appearing toxin binding sites in sister muscle cultures. On day 0,60 muscle cultures were prepared. Thirty cultures were treated on day 1 with $1 \mu \mathrm{M}$ unlabeled $\alpha$-BT to block existing ACh receptors. Then the appearance of new receptors was quantiated by treating the cultures with ${ }^{125} \mathrm{I}-\alpha-\mathrm{BT}$ at a later time. The mean \pm standard deviation in sister cultures begun on day 1 is shown by the solid symbols. The remaining 30 sister muscle cultures were blocked with unlabeled $\alpha$-BT on day 4 and incorporation of new toxin binding sites followed (open symbols). The curves represent the predicted rate of appearance of toxin binding according to the equation

$$
R_{t}=\left(1-e^{-t \beta}\right) \alpha / \beta
$$

where $R_{\mathrm{t}}$ is the number of binding sites at time $t, \beta$ is the degradation rate constant of $72-\mathrm{hr}^{-1}$, and $\alpha$ corresponds to the initial incorporation rate for day 1 and for day 5 measured as the slope between 0 and $6 \mathrm{hr}$.
TABLE II

Appearance of new toxin binding sites

\begin{tabular}{ccccc}
\hline Experiment No. & Day $^{a}$ & $\begin{array}{c}\text { Incorporation } \\
\text { Rate }^{t}\end{array}$ & Equilibrium $^{c}$ & $\begin{array}{c}\text { Binding } \\
\text { Sites/hr }\end{array}$ \\
\hline & & $\begin{array}{c}\text { fmol of binding }_{\text {sites/hr }} \\
\text { fmol of binding } \\
\text { sites }\end{array}$ & $\%$ \\
1 & 1 & 0.30 & 20 & 1.5 \\
2 & 1 & 0.28 & 21 & 1.3 \\
3 & 1 & 0.22 & 18 & 1.2 \\
4 & 2 & 0.27 & 20 & 1.4 \\
5 & 2 & 0.41 & 38 & 1.1 \\
6 & 3 & 0.26 & 22 & 1.2 \\
7 & 4 & 0.21 & 20 & 1.0 \\
\hline
\end{tabular}

${ }^{a}$ The day on which the experiment began.

${ }^{b}$ Mean incorporation rate computed from three sister cultures.

c The number of binding sites measured on 6-day sister cultures.

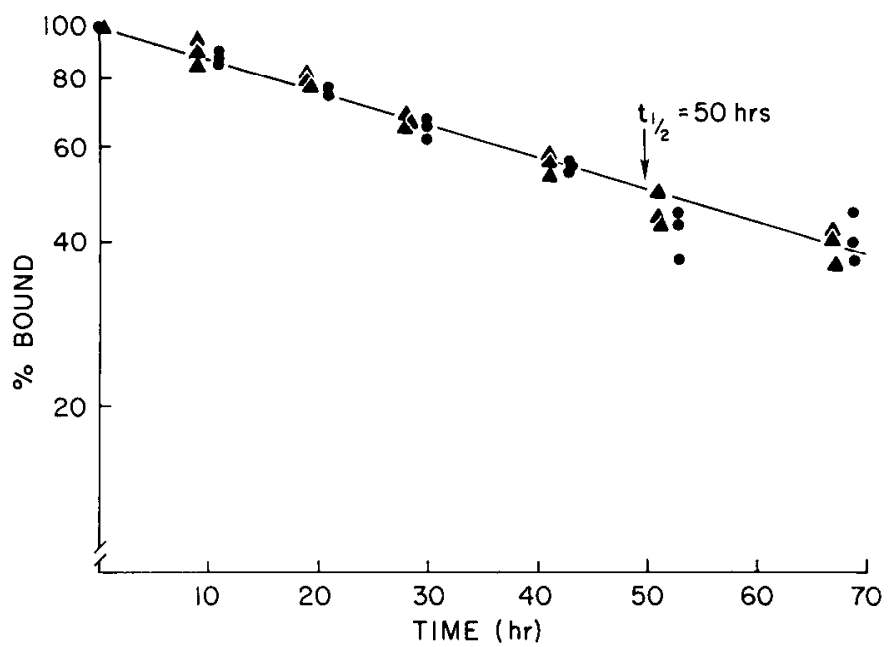

Figure 3. Degradation of toxin binding sites in sister muscle cultures (O) and 3-day nerve and muscle cultures (A). Sixty cultures (using approximately three embryos per culture) were prepared on day 0 and to each of 30 cultures three neural tubes were added at the time of plating. All of the 60 cultures were given 3 days to develop and then were labeled with ${ }^{125} \mathrm{I}-\alpha-\mathrm{BT}$. The percentage of cpm bound then was computed at different times following labeling by measuring cpm bound to coverslip/ (cpm bound to coverslip $+\mathrm{cpm}$ released into growth medium). Each point was corrected for release due to nonspecific release of radioactivity by separation of high and low molecular weight species on a P-2 column. The straight line was fitted by eye.

sponds to nondegraded ${ }^{125} \mathrm{I}-\alpha$-BT (Berg and Hall, 1975; Devreotes and Fambrough, 1975). The high molecular weight fraction constituted $51 \%$ of the total released radioactivity at $6 \mathrm{hr}$ and $16 \%$ at $70 \mathrm{hr}$. However, no consistent increase in the absolute amount of high molecular weight radioactivity was recorded between 6 and $70 \mathrm{hr}$. The high molecular weight radioactivity that was present probably resulted from a release of ${ }^{125} \mathrm{I}-\alpha-\mathrm{BT}$ from nonspecific binding sites during the first 6 -hr incubation period. These data demonstrate that dissociation of the toxin-receptor complex does not contribute to the estimates of receptor degradation and therefore must occur on a much slower time scale.

Degradation curves are based on radioactivity released from the total population of labeled receptors. The ex- 
TABLE III Degradation of toxin binding sites

\begin{tabular}{cccc}
\hline Experiment No. & Neural Tube & Day" & Half life \\
\hline & & & $h r$ \\
2 & $+^{b}$ & 1 & 52 \\
3 & + & 2 & 50 \\
4 & $-{ }^{c}$ & 2 & 50 \\
5 & - & 3 & 56 \\
& - & 4 & 54
\end{tabular}

"The day on which the experinent began.

${ }^{b}$ Co-cultures with neural tube cells.

Cultures without neural tube cells.

ponential decline in bound toxin (Fig. 3) suggests that the degradation of all receptors is governed by a single kinetic process. Since aggregated receptors constitute only a fraction of the total receptor population, it is possible that an altered rate of degradation in response to aggregation would pass undetected. Therefore we can not draw any conclusions regarding the possible effect of aggregation on the rate of receptor turnover.

\section{Discussion}

Cell culture of embryonic Xenopus nerve and muscle has furthered our understanding of the control of ACh receptor distribution and function during development (Anderson and Cohen, 1977; Anderson et al., 1977; Kidokoro et al., 1980; Brehm et al., 1982). However, no information has been available on $\mathrm{ACh}$ receptor metabolism by Xenopus muscle or, for that matter, by any amphibian skeletal muscle. This study indicates that ACh receptor metabolism occurs in a manner similar to that of avian and mammalian skeletal muscle. Incorporation of newly synthesized receptors in Xenopus muscle occurs at a constant rate while the degradation of labeled ACh receptors in Xenopus follows first order kinetics. In Xenopus the estimated average half-life for receptors is $52 \mathrm{hr}$ at $20^{\circ} \mathrm{C}$, corresponding to $1.2 \%$ to $1.4 \%$ of the cell surface receptors turned over per hour. Therefore, this degradation rate does approximate the measured incorporation rate on day 5 , when a steady state number of receptors was observed.

Measurements of metabolic stability of ACh receptors in post-hatch chick (Burden, 1977) and embryonic rat (Michler and Sakmann, 1980; Reiness and Weinberg, 1982) muscle have indicated that two different receptor types can be observed on the basis of differences in degradation rates. In both cases the adult receptor type is degraded more slowly than the embryonic type. Recently, two receptor types, based on differences in functional properties, have been identified on embryonic Xenopus muscle (Brehm et al., 1982). The two types differ in terms of mean channel open time and conductance. The presence of two functionally distinct receptor types raised the possibility that the two types also had corresponding differences in metabolic stability. This possibility was examined by measuring receptor turnover in cells grown under conditions which led to changes in functional properties of receptors. Cells were first compared for any change in metabolic stability of ACh receptors over the 6-day period following dissociation. During the 6-day culture period the mean channel open time of ACh receptors has been shown to decrease from 4 msec to less than 1 msec. This change parallels the decrease in mean channel open time observed with muscle in vivo (Kullberg et al., 1981). However, the results of this study indicate no corresponding change in receptor stability over this time period (Table III). We searched further for a correspondence between changes in functional properties and metabolic properties of receptors by comparing muscle cell cultures to muscle cocultured with neural tube cells. The addition of neural tube cells to muscle culture dramatically alters the mean channel open time of $\mathrm{ACh}$ receptors on both nerve-contacted and noncontacted muscle cells. Interpreted in terms of two separate channel types, addition of neural tube decreases the adult type receptor from an estimated $75 \%$ to $25 \%$ of the total receptor number over a 3-day period (Brehm et al., 1982). However, no difference in receptor stability was observed between muscle cell culture and muscle cocultured with neural tube (Table III; Fig. 3).

It could be argued that a change in metabolic stability following neural tube addition would be missed if one functionally distinct receptor type was degraded very slowly relative to the 70 -hr measurement period. If this were the case we would always be measuring the receptor with the faster degradation rate. A receptor half-life of greater than $100 \mathrm{hr}$ is, in fact, characteristic of junctional receptors in adult rat muscle (Berg and Hall, 1975; Michler and Sakmann, 1980). Two observations argue that neither form of functionally distinct receptor is degraded with a correspondingly slow rate in embryonic Xenopus muscle. First, an estimated 2-fold difference in the proportion of functionally distinct receptor types exists between muscle cell culture and muscle cells cocultured with neural tube. This difference is sufficiently large that a shift in the slope of the degradation curve (Fig. 3) should have resulted if one of the functionally distinct receptor types were degraded with a very slow half-life. Second, although coculture with neural tube affects the functional properties of receptors, it has no effect on either receptor number (Table I) or receptor density (Kidokoro and Gruener, 1982). If one functionally distinct receptor were more stable than the other, a difference in the receptor number and density would follow coculture with neural tube cells. Therefore, it is likely that a change in functional properties of $\mathrm{ACh}$ receptors in embryonic Xenopus muscle occurs independent of changes in receptor stability. This finding is in agreement with reports on embryonic rat muscle which indicate that changes in receptor stability and function occur asynchronously in time (Michler and Sakmann, 1980; Reiness and Weinberg, 1982).

Metabolic stabilization of $\mathrm{ACh}$ receptors has been shown to occur during development of mammalian (Michler and Sakmann, 1980; Reiness and Weinberg, 1982) and avian (Burden, 1977) muscle. It is likely that stabilization of receptors also occurs in amphibian muscle as well (Frair and Cohen, 1981). However, no such stabilization of receptors was detected on cultured Xenopus embryonic muscle. This may reflect the fact that no stabilization of receptors has occurred. Alternatively, the number of receptors which have undergone stabilization may have been too few to be detected by our measure- 
ment technique. The findings of this study support the idea that if stabilization of $\mathrm{ACh}$ receptors occurs during embryonic development of Xenopus muscle, it occurs without alterations in the functional properties. This apparent absence of interdependence between receptor function and stability is shared by avian, mammalian, and amphibian muscle alike.

\section{References}

Anderson, M. J., and M. W. Cohen (1977) Nerve-induced and spontaneous redistribution of acetylcholine receptors on cultured muscle cells. J. Physiol. (Lond.) 235: 655-691.

Anderson, M. J., M. W. Cohen, and E. Zorychta (1977) Effects of innervation on the distribution of acetylcholine receptors on cultured muscle cells. J. Physiol. (Lond.) 268: 731-756.

Berg, D., and Z. Hall (1975) Loss of $\alpha$-bungarotoxin from junctional and extrajunctional acetylcholine receptors in rat diaphragm muscle in vivo and in organ culture. J. Physiol. (Lond.) 252: 771-789.

Brehm, P., J. H. Steinbach, and Y. Kidokoro (1982) Channel open time of acetylcholine receptors on Xenopus muscle cells in dissociated cell culture. Dev. Biol., 91: 93-102.

Burden, S. (1977) Acetylcholine receptors at the neuromuscular junction: Developmental changes in receptor turnover. Dev. Biol. 61: 79-85.

Card-Linden, D., and D. Fambrough (1979) Biosynthesis and degradation of acetylcholine receptors rat skeletal muscle. Effects of electrical stimulation. Neuroscience 4: 527-538.

Devreotes, P., and D. M. Fambrough (1975) Acetylcholine receptor turnover in membranes of developing muscle fibers. J. Cell Biol. 65: 335-358.

Fischbach, G. D., and S. Schuetze (1980) A postnatal decrease in acetylcholine channel open time at rat end-plates. J. Physiol. (Lond.) 303: 125-137.
Frair, P., and M. W. Cohen (1981) Degradation of acetylcholine receptors in innervated myotomes of Xenopus laevis maintained in organ culture. Soc. Neurosci. Abstr. 7: 838.

Kidokoro, Y., and R. Gruener (1982- Distribution and density of $\alpha$-bungarotoxin binding sites in innervated and non-innervated muscle cells in culture. Dev. Biol. 91: 78-85.

Kidokoro, Y., M. J. Anderson, and R. Gruener (1980) Changes in synaptic potential properties during acetylcholine receptor accumulation and neurospecific interactions in Xenopus nerve-muscle cell culture. Dev. Biol. 78: 464-483.

Kullberg, R., P. Brehm, and J. H. Steinbach (1981) Nonjunctional acetylcholine receptor channel open time decreases during development of Xenopus muscle. Nature 289: 411413.

Michler, A., and B. Sakmann (1980) Receptor stability and channel conversion in the subsynaptic membrane of developing mammalian neuromuscular junction. Dev. Biol. 80: 117.

Reiness, C. G., and Z. Hall (1981) The developmental change in immunological properties of the acetylcholine receptor in rat muscle. Dev. Biol. 81: 324-331.

Reiness, C. G., and C. B. Weinberg (1982) Metabolic stability of acetylcholine receptors and newly formed neuromuscular junctions in rat. Dev. Biol., in press.

Sakmann, B., and H. R. Brenner (1978) Changes in synaptic channel gating during neuromuscular development. Nature 276: 401-402.

Schuetze, S. (1980) The acetylcholine channel open time in chick muscle is not decreased following innervation. J. Physiol. (Lond.) 303: 111-124.

Schuetze, S., and G. D. Fischbach (1978) Channel open time decreases post-natally in rat synaptic acetylcholine receptors. Soc. Neurosci. Abstr. 4: 1195.

Vogel, Z., A. J. Sytkowski, and M. W. Nirenberg (1972) Acetylcholine receptors of muscle grown in vitro. Proc. Natl. Acad. Sci. U. S. A. 69: 3180-3184. 